\title{
Apresentação ao dossiê "Esportes e fontes orais"
}

\author{
Bernardo Buarque de Holanda* \\ ORCID iD 0000-0001-7781-4684 \\ Centro de Pesquisa e Documentação de História Contemporânea do Brasil, Fundação Getúlio Vargas, São Paulo, Brasil
}

\section{Lívia Magalhães*}

ORCID 0000-0002-0806-2578

Universidade Federal Fluminense, Instituto de História, Niterói, Brasil

O presente dossiê é fruto de um campo de estudos que está prestes a completar 40 anos. Em artigo de balanço escrito para o Boletim de Informaçáo Bibliográfica, o antropólogo Luiz Henrique de Toledo (2001) balizou o ano de $1982^{1}$ como data matricial para o início das pesquisas acadêmicas dedicadas aos esportes, com particular atenção ao futebol, no âmbito das Ciências Sociais. A referência, por suposto, diz respeito à coletânea organizada por Roberto DaMatta, intitulada Universo do futebol: esporte e sociedade, que reunia pesquisadores da área de antropologia social, em formação na pós-graduação do Museu Nacional, do Rio de Janeiro, em princípios daquele decênio.

Em busca de uma terminologia para o campo, Toledo, nesse mesmo texto, considerava mais apropriada a denominaçáo "antropologia das práticas esportivas", posto que captava o dinamismo conceitual e uma compreensão mais lata do gradiente de atividades dos esportes. Em acréscimo, evitava o enrijecimento do objeto reificado, segundo mais uma nova e cômoda setorizaçáo: antropologia dos esportes. Seja

Doutor em História Social da Cultura pela Pontifícia Universidade Católica do Rio de Janeiro (PUCRio). Professor da Escola de Ciências Sociais (CPDOC-FGV). E-mail: bernardo.hollanda@fgv.br.

Doutora em História pela Universidade Federal Fluminense (UFF). Professora do Instituto de História da Universidade Federal Fluminense (UFF). E-mail: liviagm@id.uff.br.

1 A rigor, poder-se-ia recuar ainda mais temporalmente, uma vez que a dissertação de mestrado da antropóloga Simoni Lahud Guedes, Futebol: instituição zero, defendida no Museu Nacional/UFRJ, remonta ao ano de 1977. 
como for, o fato é que nas últimas quatro décadas geraçóes de pesquisadores, não apenas da antropologia, vêm se interessando em investigar atores, eventos e relaçóes sociais associadas às práticas e às representaçóes esportivas, aos chamados, por outro antropólogo, "futebóis" (Damo, 2006), em suas diferentes escalas, matrizes e dimensôes. Junto às pós-graduaçôes da Educação Física, envolvidas de maneira constitutiva com a temática, uma série de historiadores, sociólogos, internacionalistas e até cientistas políticos têm procurado trazer contribuiçóes ao fenômeno esportivo, em suas distintas modalidades, ainda que com a preponderância para o futebol profissional.

$\mathrm{Na}$ História, em particular, referências inaugurais ocorreram no início dos anos 2000, com os livros dos historiadores Leonardo Pereira e Vitor Melo, respectivamente: Footballmania: uma história social do futebol no Rio de Janeiro (1902-1938) e Cidade sportiva: primórdios do esporte no Rio de Janeiro. O impacto, direto e indireto, desses trabalhos, ambos resultantes de teses de doutorado em instituiçóes como a Unicamp e a UFRJ, facultou o início da estruturação de uma rede de pesquisadores no país e assim se sucedeu ano a ano nos simpósios temáticos da Associação Nacional de História, a Anpuh (Figols, 2018).

É necessário ademais mencionar na gênese desse processo os trabalhos de orientação e as frentes de pesquisa desenvolvidas pelo professor Francisco Carlos Teixeira da Silva (UFRJ), desde a segunda metade dos anos 1990, com o projeto Memória social dos esportes, tornado público à época sob os auspícios da Faperj, em títulos instigantes e originais como São Januário: arquitetura e história.

Pode-se dizer que esse crescimento das pesquisas reverberou também na História Oral, em especial, na ABHO e na sua revista, a História Oral (HO), no decorrer dos anos 2010. Até então as fontes primordiais para investigaçôes de desempenhos em Copas do Mundo, em Jogos Olímpicos, entre outros eventos menos espetaculosos relacionados aos esportes, pautaram-se por registros escritos, notadamente os jornais e as revistas de circulação pública, bem como, em menor escala, os arquivos de clubes, de federaçóes e de entidades congêneres.

Embora possa haver referências anteriores, ao longo da década de 2010 os registros orais passam a ser incorporados pouco a pouco à agenda de estudos do tema, a exemplo do projeto institucional "Futebol, memória e patrimônio", desenvolvido pelo CPDOC-FGV, com apoio da Fapesp, por meio de uma série de dezenas de depoimentos gravados de ex-futebolistas brasileiros, coletados em parceria com o Museu do Futebol, equipamento público situado na cidade de São Paulo.

Tal projeto, desenvolvido entre 2011 e 2012, no horizonte da Copa do Mundo FIFA de futebol masculino, realizado no Brasil em 2014, permitiu que um primeiro artigo vinculado à temática fosse publicado na revista História Oral, em 2017 (Hollanda). Nessa esteira, outro texto (Ribeiro), dedicado à prática do futebol de várzea em Belo Horizonte, veio a lume no dossiê intitulado "Cidades, personagens e ocupaçóes de espaços" pela $\mathrm{HO}$ em 2019. 
Em paralelo, os encontros regionais e nacionais da ABHO começaram em 2012 a organizar Simpósios Temáticos (STs) em torno das pautas esportiva e futebolística. A frequência tornou-se contínua a partir de 2016, quando da realização da décima terceira edição do evento nacional, em Porto Alegre, graças à iniciativa da professora Silvana Goellner (UFRGS). O ST teve sequência em 2017, no Encontro Regional Sudeste de História Oral, ocorrido em Belo Horizonte, com a organização do pesquisador mineiro Raphael Rajáo; já em 2018 foi a vez do Encontro Nacional acontecido em Campinas, sendo coordenado por Bernardo Buarque (CPDOC-FGV); em 2019, a Sessão Regional Sudeste da ABHO voltou a organizar um Simpósio sobre esportes no evento do Rio de Janeiro, tendo como coordenadora Vivian Fonseca (CPDOC-FGV).

Em 2020, em virtude da pandemia da Covid-19, não houve tempo hábil para a organização do ST online no Encontro Nacional de Belém, mas a apresentação "Podem as torcidas de futebol ser movimentos sociais?" foi feita por um dos organizadores deste dossiê, em parceria com o professor Felipe Tavares Lopes (Uniso). Para 2021, estão previstos Simpósios sobre esportes em ao menos três regiôes: Sul, Sudeste e Nordeste.

A busca por referenciais da História Oral para os estudos dos esportes encontra guarida também em âmbito internacional. Um dos autores mais reconhecidos da área, o historiador italiano Alessandro Portelli, dedica-se ao assunto em alentado capítulo denominado "Esporte, trabalho e política numa cidade industrial", uma densa abordagem da dimensão identitária e comunitária do futebol na Itália da segunda metade do século XX, tal como testemunhada por seus entrevistados, em texto publicado em português na coletânea Ensaios de história oral (2010).

Mais recentemente, a prestigiada revista acadêmica The International Journal of the History of Sport, pertencente à editora e publisher inglesa Taylor \& Francis, publicou em dois volumes o dossiê Oral history and sports, organizado pelo pesquisador irlandês Mike Cronin (Boston College/Dublin), com mais de uma dezena de artigos selecionados.

É possível dizer que todos esses fatores, em retrospecto, concorreram para a proposição deste número "Esportes e fontes orais". Acreditamos que ele torna possível não apenas uma reuniâo de escritos capazes de enfeixar a produçáo dedicada à interface esportiva com a História Oral, mas também se pretende que o dossiê sirva de estímulo e de referência à ampliação desse campo, em particular as pesquisas amparadas em registros que se valem das ferramentas e da metodologia praticada pela comunidade de "oralistas" no Brasil.

Os dez textos selecionados para esta edição ilustram a variedade de temáticas, práticas e áreas de interesse que trabalham com a metodologia da História Oral para a análise dos fenômenos esportivos. Se o futebol é a temática dominante, a presença de outras modalidades, assim como as diferentes abordagens sobre as experiências futebolísticas, reforça a expansão do campo de estudos em tela. $\mathrm{O}$ artigo que abre o dossiê "Reflexóes teórico-metodológicas acerca do futebol e fontes orais", de Sérgio Settani Giglio e Marcel Tonini, demonstra bem essa ponderaçáo. A partir de entrevistas 
realizadas com jogadores de futebol que atuaram no exterior, os autores retomam debates e salientam como memória, lembrança e esquecimento enfatizam as diferenças entre a entrevista com base na metodologia da História Oral e a jornalística.

A seguir, dois artigos partem dos Jogos Olímpicos de Verão e seus significados - desde a relação com a identidade nacional como a rotina de preparação para as competiçóes - e propóem instigantes usos da História Oral como metodologia para trazer questôes subjetivas e coletivas. William Douglas de Almeida e Kátia Rubio, no texto "Imigrantes no esporte olímpico brasileiro: protagonismo e identidade", optam pela Narrativa Biográfica para apresentar a trajetória de migrantes que foram naturalizados e que representaram o Brasil em competiçóes olímpicas.

Já no artigo "Seleçẫo Brasileira de Handebol Feminino: da primeira convocação à conquista da vaga Olímpica (1983-2000)", Suéllen de Souza Andres e Silvana Vilodre Goellner baseiam-se em entrevistas com ex-atletas e um ex-técnico para analisar a trajetória dos primórdios da seleção de handebol feminino do Brasil, destacando como aspectos centrais possibilitaram sua criaçáo e o desenvolvimento de torneios continentais, bem como os intercâmbios europeus.

Por sua vez, Ivo Lopes Müller Júnior, Pauline Iglesias Vargas e André Mendes Capraro reforçam a diversidade de abordagens e modalidades que são objeto de interesse das pesquisas atuais no artigo "A disseminação do Muay Thai no Brasil: narrativas e memórias dos mestres pioneiros". Como destacam os autores, a partir de 1990, com o êxito de lutadores, o Muay Thai tornou-se uma das modalidades de luta mais praticadas no país. Assim, a partir da trajetória de Nélio Naja, suposto introdutor da prática no Brasil, o artigo levanta a construção memorialística feita pelo atleta e a relação da mesma com a consolidação e expansão da modalidade em território brasileiro.

Desse ponto em diante, o futebol volta a ser o eixo dos artigos do dossiê. Porém, é importante ressaltar as diversidades de temáticas e compreensôes de atores e análises do universo futebolístico apresentados. João Manuel Casquinha Malaia dos Santos, por exemplo, em "Recordar é viver!: cânticos de torcida, memória e fontes orais", utiliza-se dos cânticos de torcidas e das entrevistas como metodologia para seu trabalho. $\mathrm{O}$ autor destaca o caráter de oralidade e das possibilidades de contrapor as diferentes fontes entrevistas e cânticos - a partir da abordagem analítica da História Oral para trabalhar tradiçóes, memórias e identidades dos torcedores.

Em "Não me sai da memória: história oral e futebol no Vale do São Francisco", Francisco Demetrius Luciano Caldas e Bruno Otávio de Lacerda Abraháo trazem uma perspectiva regional, que transpóe o circuito dos grandes clubes. Como destacam os autores, a história do mais importante torneio amador de futebol no Vale do Sáo Francisco pode ser reescrita considerando elementos como, por exemplo, narrativas pessoais e a dimensão simbólica da experiência para os diversos protagonistas (não apenas jogadores, mas aqui também incluídos os jornalistas entre os entrevistados).

No mesmo caminho de pensar um futebol além do circuito do mainstream clubístico, o artigo de Raphael Rajăo Ribeiro, "Vai ter excursão? - Futebol de várzea, 
lazer popular e patrimônio cultural em Belo Horizonte (anos 1940-1980)", também foca na prática amadora e nos relatos de seus muitos personagens. Utilizando fontes orais, jornalísticas e das próprias agremiaçóes, Ribeiro analisa como se deu a inserção em uma cultura popular - posteriormente declarado patrimônio imaterial do município de Belo Horizonte - das excursóes de clubes de várzea entre os anos de 1940 e 1980.

No artigo que segue, "O clube como vocação: os sentidos da política nas fontes orais dos presidentes de futebol no Rio de Janeiro", Luiz Guilherme Burlamaqui, por sua vez, propóe discutir um tema ainda pouco considerado nos estudos sobre entidades esportivas: as trajetórias dos dirigentes e, especialmente, o caminho de ascensão dos mesmos nos quadros sociais hierárquicos dos clubes. Para o autor, as fontes orais permitem uma abordagem e um olhar diferentes, que ajudam a reconstituir a visão de mundo desses grupos, assim como a maneira e a forma pela qual imaginam e pensam o fazer político.

Já o artigo de Nathália Fernandes Pessanha retoma o lugar do torcedor, mas com base em uma perspectiva de gênero. Em "Mulheres nas arquibancadas: as performances e os enfrentamentos das torcedoras cariocas", a autora questiona o espaço do torcer em sua hegemonia masculina e traz discussôes sobre a vivência e os muitos enfrentamentos das mulheres que se identificam como torcedoras, mas que não fazem parte de grupos organizados. Para Pessanha, as arquibancadas tornam-se, assim, locus de reprodução das manifestaçóes de opressão, misoginia e machismo que marcam a sociedade brasileira.

Finalmente, o artigo de Letícia Portella Milan, "O Grêmio Esportivo Rui Barbosa: um espaço comunitário dos residentes do bairro do Porto (Pelotas-RS, 1986-2004)", fecha o dossiê com a proposta de pensar um clube amador segundo a ideia de um "lugar de memória" de Pierre Nora, discutindo sociabilidades, vivências e o cotidiano dos moradores e frequentadores.

Portanto, os diferentes e instigantes artigos que compóem este dossiê reforçam a leitura de que a expansão do campo de estudos dos esportes se fortalece ao propor uma interface com a História Oral. Novas perguntas, inquietaçóes e possibilidades emergem e doravante, na esteira das pesquisas do presente volume, muitas mais virão...

\section{Referências}

DAMATTA, Roberto. Universo do futebol: esporte e sociedade. Rio de Janeiro: Ediçóes Pinakotheque, 1982.

FIGOLS, Victor de Leonardo. O lugar do futebol nos simpósios da Associação Nacional de História (ANPUH): um balanço de 1961 a 2017. Revista Hydra, Sáo Paulo, v. 3, n. 5, p. 9-73, 2018.

GUEDES, Simoni Lahud. Futebol: instituição-zero. Dissertaçáo (Mestrado em Antropologia Social) - UFRJ, Museu Nacional, Rio de Janeiro, RJ, 1977. 
HOLLANDA, Bernardo Borges Buarque de. Futebol, memória e relatos orais: a trajetória de exjogadores da Seleção Brasileira e as narrativas memorialísticas das Copas do Mundo FIFA, entre 1954 e 1982. História Oral, v. 20, n. 1, p. 101-123, 2017.

LOPES, Felipe Tavares Paes; HOLLANDA, Bernardo Buarque de. Podem as torcidas de futebol ser movimentos sociais? In: ENCONTRO NACIONAL DE HISTÓRIA ORAL, 15., 2020, Belém. Anais... Rio de Janeiro: ABHO, 2020.

MALHANO, Clara; MALHANO, Hamilton. Memória social dos esportes: São Januário arquitetura e história. Rio de Janeiro: Mauad: Faperj, 2002.

MELO, Vitor Andrade de. Cidade sportiva: primórdios do esporte no Rio de Janeiro. Rio de Janeiro: Relume Dumará, 2001.

PEREIRA, Leonardo Afonso de Miranda. Footballmania: uma história social do futebol no Rio de Janeiro (1902-1938). Rio de Janeiro: Editora Nova Fronteira, 2000.

PORTELLI, Alessandro. Esporte, trabalho e política numa cidade industrial. In: PORTELLI, Alessandro. Ensaios de história oral. São Paulo: Letra e Voz, 2010. p. 131-158.

RIBEIRO, Raphael Rajão; HOLLANDA, Bernardo Borges Buarque de. História oral, prática futebolística e cidades no Brasil: conflitos e apropriaçôes nas narrativas de ocupação dos campos de futebol de várzea de Belo Horizonte. História Oral, v. 2, n. 22, p. 33-57, 2019.

TOLEDO, Luiz Henrique de Toledo. Futebol e teoria social: aspectos da produção científica brasileira (1982-2002). Boletim de Informação Bibliográfica, São Paulo, n. 52, p. 133-165, 2001.

SILVA, Francisco Carlos Teixeira da (Org.). Memória social dos esportes: futebol e política - a construção de uma identidade nacional. Rio de Janeiro: Mauad: Faperj, 2006. 